\title{
ANÁLISE DA PRECIPITAÇÃO PLUVIOMÉTRICA NA BACIA HIDROGRÁFICA DO RIO IJUÚ-RS NO PERÍODO DE 2001 A 2015
}

\author{
Vagner Apollo Duarte ${ }^{(a)}$, Cássio Arthur Wollman ${ }^{(b)}$, Richard kohler Marczewski ${ }^{(c)}$. \\ (a) Departamento de Geografia Universidade Fedeal de santa Maria - RS, vagneraduarte@ hotmail.com \\ (b) Departamento de Geografia Universidade Fedeal de santa Maria - RS, cassio_geo@yahoo.com.br \\ (c) Departamento de Geografia Universidade Fedeal de santa Maria - RS, richard_kohler@hotmail.com
}

\section{Eixo: Climatologia em Diferentes Níveis Escalares: Mudanças e Variabilidade}

\begin{abstract}
Resumo
O objetivo deste trabalho é analisar a variabilidade da precipitação pluviométrica na Bacia Hidrográfica do Rio Ijuí-RS entre 2001 à 2015. Para a realização deste trabalho utilizou-se dados de 13 postos localizados dentro da bacia do Rio Ijuí e foram tabulados no excel para calcular as médias de cada posto e o total médio da bacia. Os mapas foram elaborados através de ferramentas SIG's (Sistema de Informação Geográfica) no software ArcGis 10.2 desenvolvido pela ESRI e os bancos de dados utilizados foram da Fepam (Fundação Estadual de Proteção Ambiental) do Rio Grande do Sul e do IBGE (Institudo Brasileiro de Geografia e Estatistica) do senso de 2010. Os resultados são bastante satisatórios uma vez que a variabilidade da precipitação foi muito nítida de um ponto para o outro e a variação em relação á média total também foi muito singificativa dentro da Bacia Hidrográfica do Rio Ijuí-RS.
\end{abstract}

Palavras chave: Variabilidade Pluviométrica; Bacia Hidrográfica; Rio Ijuí-RS.

\section{Introdução}

Possuir o conhecimento detalhado da variabilidade das precipitações pluviométricas em bacias hidrográficas é de grande importância, pois contribui para um melhor planejamento das atividades agrícolas conforme a estação de cada cultura na qual o Rio Grande do Sul é muito forte principalmente no setor primário, mas também no setor industrial, bem como no planejamento do uso da água nas bacias hidrográficas. Neste caso, o planejamento do uso da água pode ser na geração de energia se o terreno apresentar condições favoráveis para esta atividade, planejamento para a irrigação em áreas rurais, indústriais e, para a bacia hidrográfica em geral.

Sendo assim, o presente trabalho tem como objetivo analisar a variabilidade da precipitação pluviométricas na bacia do Rio Ijuí entre os anos de 2001 a 2015. Foi utilizada esta bacia pra estudo em

DOI - 10.20396/sbgfa.v1i2017.2461 - ISBN 978-85-85369-16-3 


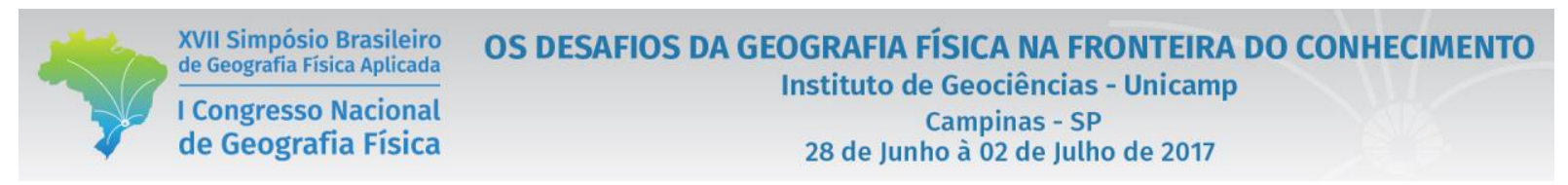

função da escassez de pesquisas sobre a pluviosidade nesta região que se trata de uma região na qual se tem uma agricultura muito forte, sendo o trigo, soja e milho como principais cultivos. (CBH) Foi utilizado o período de 15 anos devido á bacia hidrográfica do rio Ijuí não possuir dados meteorológicos com um período maior que este.

\subsection{Localização e Breve Caracterização Geográfica da Área de Estudo}

A Bacia Hidrográfica do Rio Ijuí esta situada na porção norte-noroeste do Estado do Rio Grande do Sul (figura 1), abrangendo uma área de $10.703,78 \mathrm{~km}^{2}$ abrangendo a província geomorfológica Planalto Meridional.

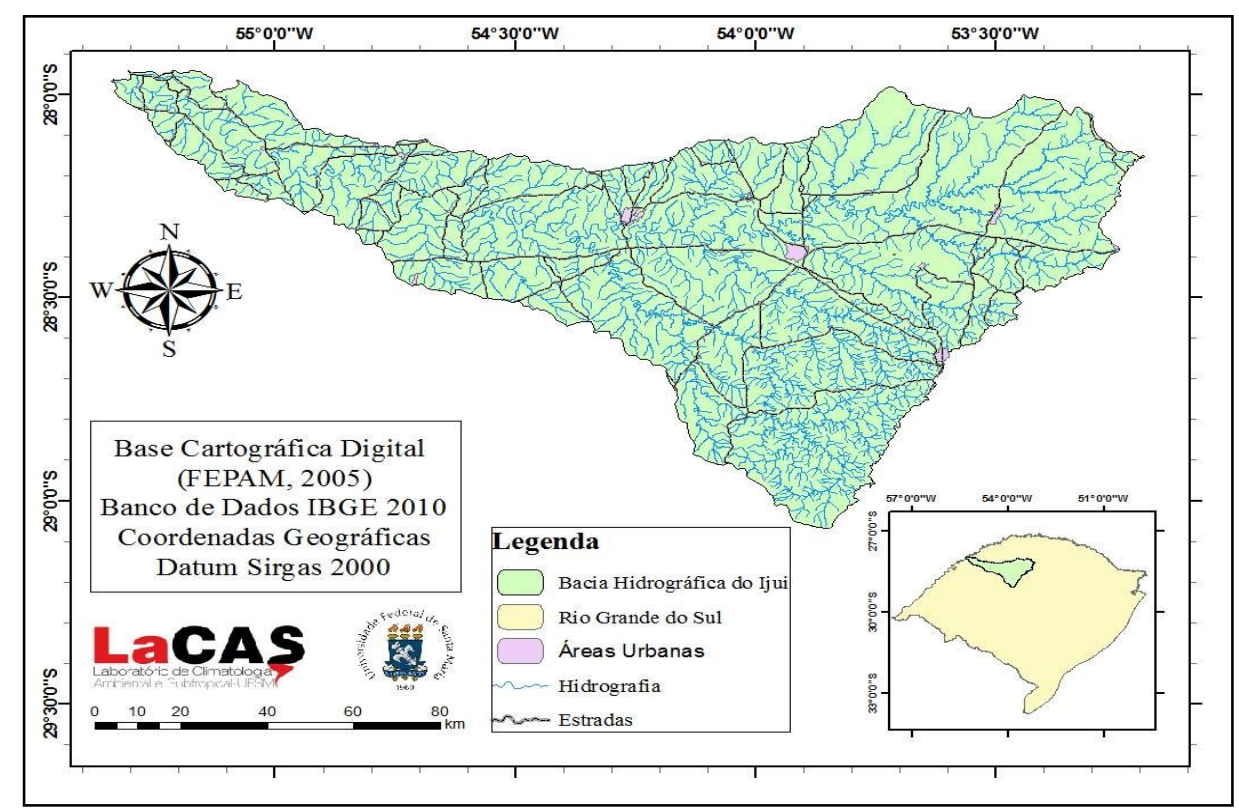

Figura 1. Mapa de Localização da Bacia Hidrográfica do Rio Ijuí - RS

Estão localizados na bacia 36 municípios entre eles Cruz Alta, Ijuí, Santo Ângelo e Tupanciretã, os maiores da bacia. Os principais cursos de água são os rios Caxambu, Potiribu, Conceição, Ijuizinho e o Rio Ijuí, e os principais usos da água se destinam a irrigação e ao abastecimento público. O uso do solo da região é principalmente composto por áreas de agricultura, campos e matas. (UAAGBH, 2008).

O mapa da figura 2 mostra a localização dos postos pluviométricos dentro da bacia Hidrográfica do Rio Ijuí, e que foram utilizados para fazer a análise da variabilidade da precipitação na bacia e que também foram os únicos com dados completos, ao todo foram utilizados 13 postos pluviométricos. 

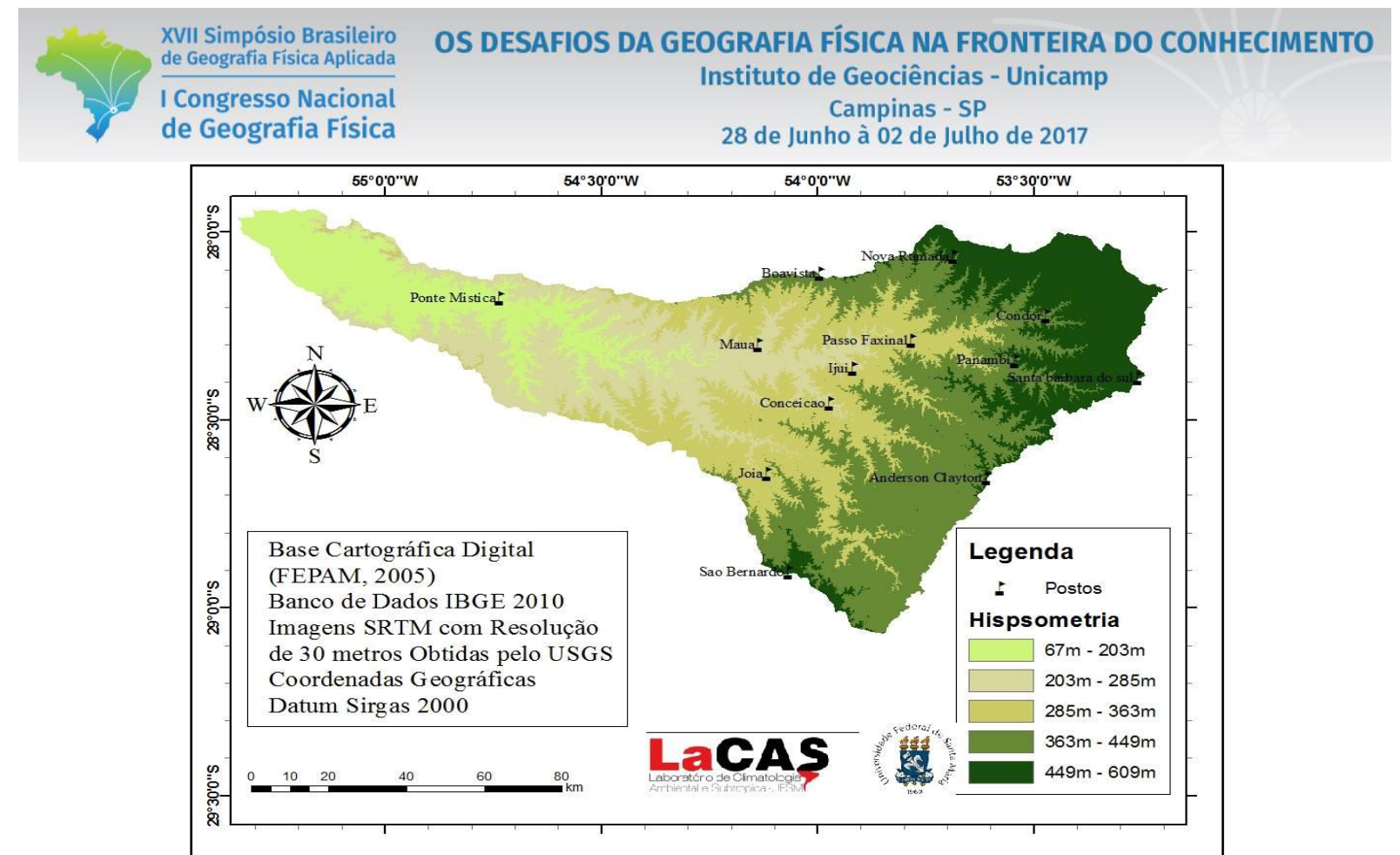

Figura 2. Mapa de localização dos Postos Pluviométricos e Hipsométrico.

Neste mapa, além dos postos pluviométricos, está a hípsometria da bacia para se ter uma noção da altitude, então, na jusante, á leste é o ponto mais baixo da bacia onde há localizado apenas um posto pluviométrico, a montante da bacia á oeste e a sul são as regiões mais altas com altitude chegando á 609 metros de altitude o que mostra que a bacia possui um desnível de mais de 500 metros o que possívelmente poderia influênciar a variabilidade da precipitação na bacia.

\section{Fundamentação Teórica.}

Zaniol (1982, p. 18) salienta que "as chuvas no Rio Grande do Sul são bem distribuídas durante todo o ano, fazendo com que a agricultura seja bem desenvolvida, com colheitas abundantes de soja, arroz, trigo milho, etc.".

Dessa forma BERTONI E TUCCI (2009) enfatizam a importância de analisar a distribuição das chuvas em bacias hidrográficas e destaca que é fundamental para a avaliação da disponibilidade hídrica de uma região hidrográfica, considerando que estudos qualitativos das precipitações pluviométricas nem sempre são parâmetros ideais para a compreensão da variabilidade das chuvas e organização quanto ao manuseio da água para fins agrícolas, domésticos, industriais, etc.

Para Galvani; Lima (2012) além da distribuição regional da precipitação pluviométrica deve ser considerado também a distribuição temporal das chuvas, pois o planejamento de atividades agrícolas e atividades econômicas de uma determinada região podem depender da distribuição sazonal das chuvas para o planejamento mais adequado de cada cultura.

DOI - $10.20396 /$ sbgfa.v1i2017.2461 - ISBN 978-85-85369-16-3 


\section{Materiais e Métodos}

Para a realização deste trabalho fez-se primeiramente um resgate teórico em relação à precipitação pluviométrica e suas características. Os dados da precipitação foram coletados do site da ANA (Agência Nacional das Aguas), os dados mensais dos 13 (Treze) postos pluviométricos utilizados nesta pesquisa foram tabulados no Software Microsoft Excel 2010 para calcular as médias dos postos e construir os gráficos das médias e das chuvas sazonais para análise dos resultados.

Os mapas foram elaborados através de ferramentas SIG's (Sistema de Informação Geografica) no software ArcGis 10.2 desenvolvido pela ESRI. Os bancos de dados utilizados foram da Fepam (Fundação Estadual de Proteção Ambiental) do Rio Grande do Sul e do IBGE (Institudo Brasileiro de Geografia e Estatistica) do senso de 2010.

\section{Resultados}

Analisando-se à distribuição e a variabilidade da precipitação pluviométrica na Bacia Hidrográfica do Rio Ijuí no decorrer destes 15 anos de análise, nota-se que a varação foi bem significativa na bacia conforme o gráfico (figura 3).

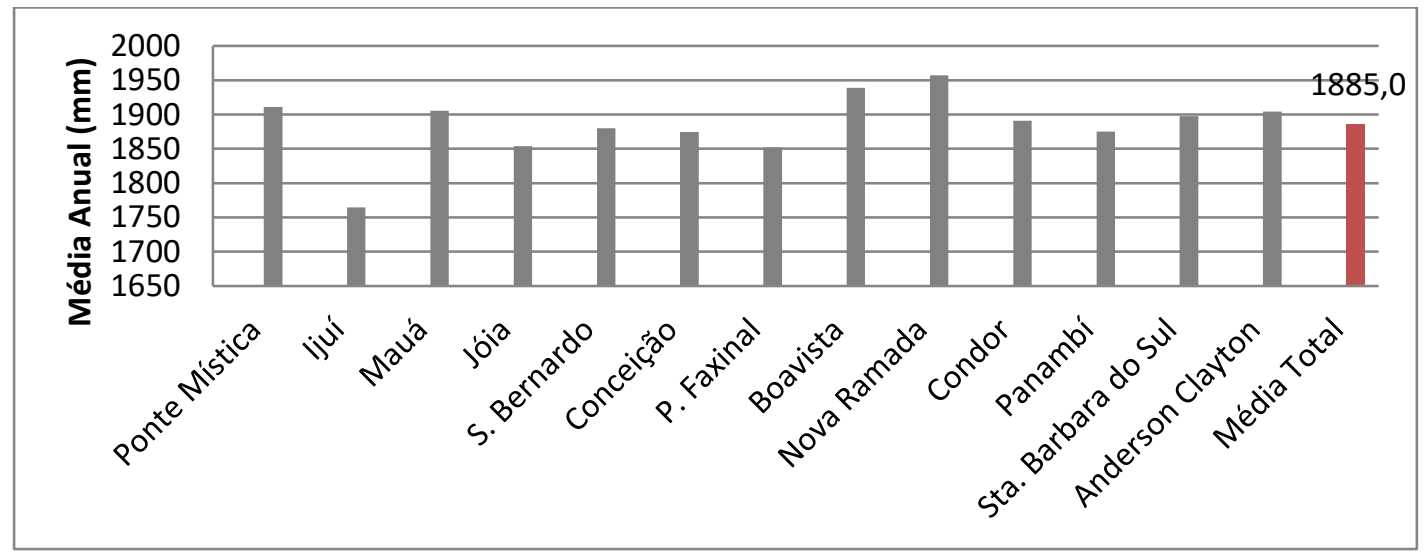

Figura 3. Médias pluviométrica dos postos e Média total da Bacia Hidrográfica do Rio Ijuí-RS.

Portanto, considerando as médias dos postos em relação á média total que é de 1885,0mm observa-se muita variação pelo fato da Bacia Hidrográfica do Rio Ijuí ter pouca influência da orografia. Por ser uma região pouco montanhosa com relevos ondulados, a variação média de um ponto para o outro é bem significativa. Podem ser destacados os postos de Nova Ramada e Boavista que obtiveram médias bem acima da média total da bacia, já os postos de Ijuí, Jóia e Passo Faxinal foram os que apresentaram médias 
bem a menos da média total, o restante dos postos se encontram dentro da normalidade destes 15 anos de análise da variabilidade pluviométrica dentro da Bacia Hidrográfica do Rio Ijuí.

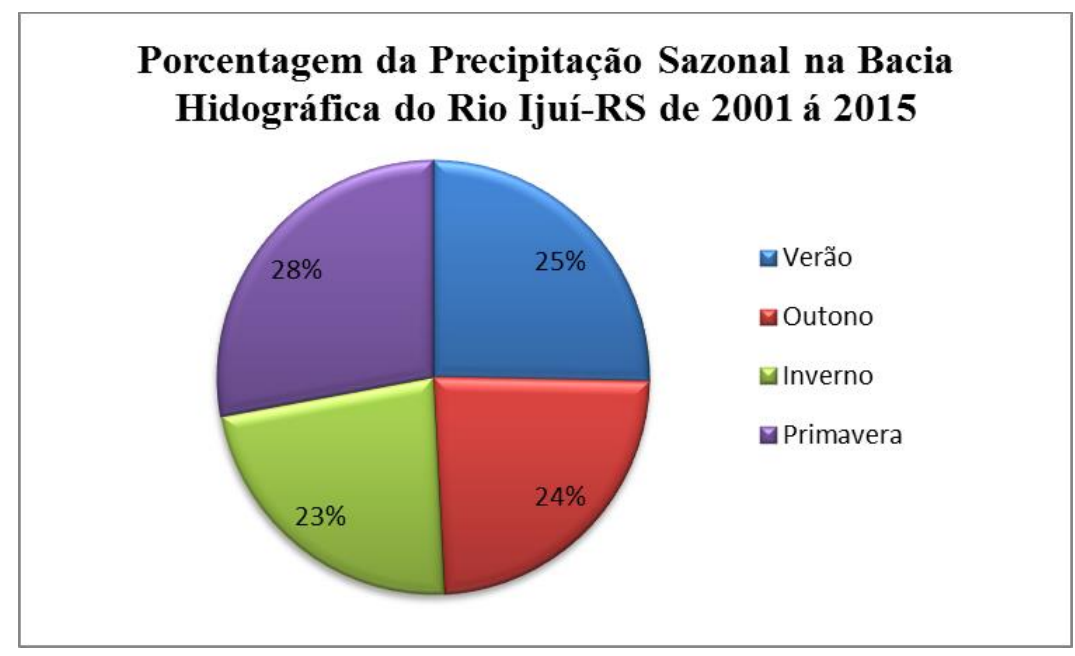

Figura 4. Precipitação Sazonal da Bacia Hídrográfica do Rio Ijuí-RS

$\mathrm{Na}$ variabilidade sazonal observa-se que é bastante variada de uma estação para a outra como mostra os valores no gráfico. Sendo assim, se tem a maior precipitação durante a primavera com $28 \%$, no verão com $25 \%$, inverno com $23 \%$ e outono com $24 \%$. Na Primavera é a estação que se tem a maior quantidade de chuva e o inverno a menor quantidade.

\section{Conclusão}

Conclui-se que as médias pluviométricas da Bacia do Rio Ijuí têm uma variabilidade muito grande de um posto para outro, até mesmo para os postos que estão localizados próximos uns aos outros como é o caso dos postos de Ijuí, Passo Faxinal e Condor. Outro ponto importante, é a distribuição sazonal, onde, a primavera é a estação mais chuvosa e o inverno se caracteriza como a estação mais seca.

\section{Referências}

ANA. Agência Nacional das Aguas. Disponível em: $<$ http://www.snirh.gov.br/hidroweb/> Acesso em: 20 fev. 2017.

BERTONI, J. C.; TUCCI, C. E. M. Precipitação. In.: TUCCI, C. E. M. (org). Hidrologia: ciência e aplicação. $4^{a}$ ed. Porto Alegre: Editora da UFRGS/ABRH, 2009. p. 177-241.

CUNHA, G.R. Meteorologia: Fatos e Mitos. Passo Fundo: EMBRAPA-CNPT, 1997.

IBGE. Instituto Brasileiro de Geografia e Estátistica: Disponível em: <http://www.ibge.gov.br/home/mapa_site/mapa_site.php\#populacao> Acesso em: 2 março. 2017.

DOI - 10.20396/sbgfa.v1i2017.2461 - ISBN 978-85-85369-16-3 
XVII Simpósio Brasileiro de Geografia Fisica Aplicada

I Congresso Nacional de Geografia Física

\section{OS DESAFIOS DA GEOGRAFIA FÍSICA NA FRONTEIRA DO CONHECIMENTO \\ Instituto de Geociências - Unicamp \\ Campinas - SP \\ 28 de Junho à 02 de Julho de 2017}

UAAGBH. Unidade de Assessoramento Ambiental Geoprocessamento - Bacias Hídrográficas. Dísponivel em:

< https://www.mprs.mp.br/areas/paibh/arquivos/diagnostico_bacia_hidrografica_rio_ijui_dat.pdf> Acesso em: 01 mar. 2017.

ZANIOL, I. Conhecendo a Terra Gaúcha. 3. ed. São Paulo: EDART, 1982. 